\title{
Flash Forward: A review of flash glucose monitoring
}

DOI:

10.1111/dme.13584

\section{Document Version}

Accepted author manuscript

Link to publication record in Manchester Research Explorer

\section{Citation for published version (APA):}

Leelarathna, L., \& Wilmot, E. G. (2018). Flash Forward: A review of flash glucose monitoring. Diabetic Medicine. https://doi.org/10.1111/dme.13584

\section{Published in:}

Diabetic Medicine

\section{Citing this paper}

Please note that where the full-text provided on Manchester Research Explorer is the Author Accepted Manuscript or Proof version this may differ from the final Published version. If citing, it is advised that you check and use the publisher's definitive version.

\section{General rights}

Copyright and moral rights for the publications made accessible in the Research Explorer are retained by the authors and/or other copyright owners and it is a condition of accessing publications that users recognise and abide by the legal requirements associated with these rights.

\section{Takedown policy}

If you believe that this document breaches copyright please refer to the University of Manchester's Takedown Procedures [http://man.ac.uk/04Y6Bo] or contact uml.scholarlycommunications@manchester.ac.uk providing relevant details, so we can investigate your claim.

\section{OPEN ACCESS}




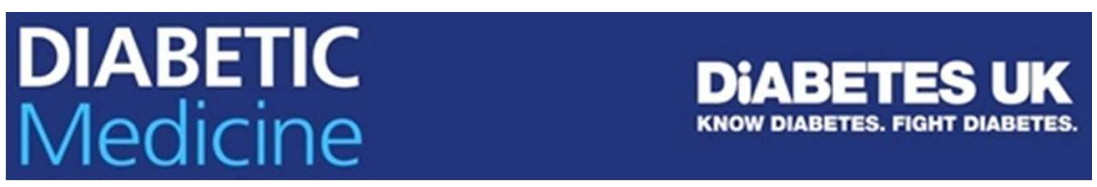

\section{Flash Forward: A review of flash glucose monitoring}

\begin{tabular}{|r|l|}
\hline Journal: & Diabetic Medicine \\
\hline Manuscript ID & DME-2017-00673.R1 \\
\hline Manuscript Type: & Review \\
\hline Date Submitted by the Author: & n/a \\
\hline Complete List of Authors: & $\begin{array}{l}\text { Lalantha, Leelarathna; Central Manchester University Hospitals NHS } \\
\text { Wilmot, Emma; Derby Teaching Hospitals NHS Foundation Trust, Diabetes }\end{array}$ \\
\hline Keywords: & devices, hypoglycaemia, self-management \\
\hline &
\end{tabular}




\title{
Flash Forward:
}

\section{A review of flash glucose monitoring}

\author{
Lalantha Leelarathna ${ }^{1,2}$, Emma G Wilmot ${ }^{3}$ \\ ${ }^{1}$ Manchester Diabetes Centre, Central Manchester University Hospitals NHS \\ Foundation Trust, Manchester Academic Health Science Centre, Manchester, UK \\ 2 Division of Diabetes, Endocrinology and Gastroenterology, Faculty of Biology, \\ Medicine and Health, University of Manchester, UK \\ ${ }^{3}$ Derby Teaching Hospitals NHS Foundation Trust, \\ Royal Derby Hospital, Uttoxeter Road, Derby, DE22 3NE
}

\section{Correspondence}

Emma G Wilmot, PhD

emma.g.wilmot@gmail.com

\section{Running title: Flash Glucose Monitoring}

Word count: Main text 4849, Abstract 245, Tables 2, Figures 3. Supplemental Tables 1.

\section{Novelty Statement:}

- The Freestyle Libre is a novel interstitial flash glucose monitor designed to replace finger-stick glucose tests, available in the UK National Health Service, subject to local health authority approval, from November 2017.

- In this narrative review, we summarise the current evidence on HbA1c, hypoglycaemia and quality of life from randomised and observational studies.

- Device accuracy data are presented, both stand alone and in comparison to existing continuous glucose monitors and blood glucose meters

- We discuss advantages, disadvantages, adverse events and summarise key practice/safety areas aimed at helping clinicians and funders to make informed decisions about its future role in diabetes management. 
Funding: None

Conflict of interest: LL reports having received speaker honoraria from Minimed Medtronic, Animas, Roche, Sanofi, Insulet and Novo Nordisk, serving on advisory panel for Abbott Diabetes Care, Roche, Sanofi, Minimed Medtronic, Animas and Novo Nordisk, grants to attend educational meetings from Sanofi, Novo Nordisk and Takeda. EGW has received speaker honoraria from Abbott Diabetes Care, Diasend, Dexcom, Eli Lilly, Minimed Medtronic, Novo Nordisk, Sanofi Aventis and has served on advisory panels for Abbott Diabetes Care, Eli Lilly, Sanofi Aventis, grants to attend educational meetings from Boehringer Ingelheim, Diasend, Novo Nordisk, Roche and Sanofi Aventis.

Acknowledgements: Authors thank Abbott Diabetes Care for sharing information on potentially interfering substances with the FreeStyle Libre sensor (Supplemental table 1) 


\begin{abstract}
:
The FreeStyle Libre flash glucose monitor became available on prescription (subject to local health authority approval) in all four nations of the United Kingdom from November 2017, a watershed moment in the history of diabetes care. Calibration free, the FreeStyle Libre is a disc worn on the arm for 14 days which is designed to largely replace the recommended 4-10 painful finger-stick blood glucose tests required each day for the self-management of diabetes. This review discusses clinical data from randomised and observational studies, considers device accuracy metrics and deliberates its popularity and the potential challenges that this new device brings to diabetes care in the UK. In randomised trials, FreeStyle Libre use is associated with a reduction in hypoglycaemia and, in observational studies, improvements in $\mathrm{HbA} 1 \mathrm{c}$. User satisfaction is high and adverse events are low. Accuracy of the FreeStyle Libre is comparable to currently available real-time continuous glucose monitors in adults, children and during pregnancy; the cost of the FreeStyle Libre is lower. Glucose data can be visualised in multiple devices and platforms, summarised in an ambulatory glucose profile to aid pattern recognition and insulin dose adjustment. There is a need for appropriate education, of both users and health care professionals, to harness the full benefits. Further randomised studies to assess the long-term impact on $\mathrm{HbA} 1 \mathrm{c}$, particularly in those with high baseline $\mathrm{HbA} 1 \mathrm{c}$ and specific age groups such as adolescence and young adults are warranted. The potential impact on complications, is yet to be realised.
\end{abstract}




\section{Introduction:}

Type 1 diabetes is a demanding lifelong condition. It requires individuals to measure blood glucose multiple times a day, facilitating insulin dose adjustment in the unrelenting endeavour to achieve normoglycaemia and minimise the future risk of micro and macrovascular complications [1]. Despite major progress in the care of people living with Type 1 diabetes, many fail to achieve modern glycaemic targets. A key barrier in achieving near normal glucose levels is this need for frequent fingerstick blood glucose monitoring, perhaps only second to the risk and fear of hypoglycaemia[2]. Pain and inconvenience are recognised reasons for nonadherence with self-monitoring of blood glucose [3, 4].

Remarkably, self-monitoring of blood glucose (SMBG) has only been an option since the 1970s [5]. Its introduction was met with controversy. Despite Sonksen reporting "insulin dosage and type were found to be much easier and more predictable than with urine-glucose analysis...hypoglycaemic episodes were less frequent, $70 \%$ of patients preferred blood-tests to urine tests and $92 \%$ would like to buy their own meter if the price was right" it was not until the 1980's that uptake became more widespread. Blood glucose monitoring is now accepted as the standard of care with NICE (NG17) recommending 4-10 measurements per day [6].

In 1999 MiniMed received FDA approval for the first retrospective continuous glucose monitor (CGM) device in the USA [7]. Since then, a number of retrospective and real-time CGM options have been introduced including MiniMed iPro, Enlite 2, Enlite Enhanced, Enlite 3 (Medtronic Inc, Northridge, CA, USA), DexCom STS (Short Term Sensor), Dexcom 3, 7, Gen 4 and 5 (Dexcom Inc, San Diego, CA, USA), and Navigator I and II (Abbott Diabetes Care, Alameda, CA, USA). These devices have been evaluated in a range of studies which have demonstrated consistent use of real-time CGM (rtCGM) is associated with improvements in $\mathrm{HbA} 1 \mathrm{c}$ and reductions in hypoglycaemia [8, 9]. However, widespread adoption of these devices has been hampered by several factors including cost, accuracy of earlier devices and user acceptability. 
Three years ago, in 2014 a new category of device was born: the FreeStyle Libre Flash Glucose Monitoring System (Abbott Diabetes Care, Alameda, CA). The FreeStyle Libre device is a white disc, worn on the arm for 14 days. As implied by the term "flash glucose monitoring" the user can obtain glucose results instantly by scanning the glucose sensor with the reader, or their mobile phone, producing realtime on-demand glucose data. A recent International Consensus on CGM has coined the term 'intermittently viewed CGM' (iCGM) to describe flash glucose monitoring [10]. While both rtCGM and the FreeStyle Llbre will allow users to monitor interstitial glucose levels, only rtCGM will alarm to alert users to the potential risk of hypoglycaemia or hyperglycaemia. With the FreeStyle Libre, such trends can only be viewed after physically scanning the sensor. A further contrast between rtCGM and the FreeStyle Libre is the need for rtCGM systems to be calibrated at regular intervals using finger-stick glucose levels. The FreeStyle Libre device, which utilises wired enzyme technology, is factory calibrated and does not need finger-stick glucose calibration during use, with stability of the sensor up to 14 days.

Abbott provided users with the option of direct on-line purchase of the FreeStyle Libre, without prior health care professional approval. This, combined with the relatively low cost and advertising led to a demand which exceeded the manufacturer's expectations. Shortly after launch, orders were suspended while a new factory was built. In this review, we aim to explore the reasons underlying the popularity of this device, discuss the clinical data, accuracy and challenges that this new device brings to diabetes care in the UK. To provide readers with most up to date information we have included both published papers as well as conference abstracts (Table 1). Data presented in some conference abstracts are preliminary in nature.

\section{Randomised controlled trials (Table 1):}

The largest study to evaluate FreeStyle Libre is the IMPACT randomised controlled multicentre European trial [11]. This study included 239 participants with well controlled $(\mathrm{HbA} 1 \mathrm{c}<=59 \mathrm{mmol} / \mathrm{mol}, 7.5 \%)$ Type 1 diabetes and intact awareness of hypoglycaemia, a third of which used CSII therapy. FreeStyle Libre use was associated with a $38 \%$ reduction in time spent in hypoglycaemia $(<3.9 \mathrm{mmol} / \mathrm{l})$ with no change in total daily insulin dose. The reduction in hypoglycaemia was achieved 
within 2 weeks, despite no training on glucose data interpretation and no health care professional contact during this period, suggesting that users intuitively understood how to react to the data (Figure 1). There was an increase in glucose time in range combined with a reduction in glycaemic variability. $\mathrm{HbA1c}$ was unchanged. FreeStyle Libre users were scanning 15/day on average, a behaviour sustained over the 6 month follow up. FreeStyle Libre utilisation was high at $>90 \%$ with high treatment satisfaction. It is important to highlight that those with impaired awareness of hypoglycaemia (IAH) were not included in IMPACT.

Reddy et al from London have assessed the FreeStyle Libre in a randomised, nonmasked parallel group study compared to rtCGM (Dexcom G5) in people with Type 1 diabetes who had experienced a severe hypoglycaemic event in the last 12 months or had impaired awareness of hypoglycaemia (IAH) (Gold score>=4) [12]. After a 2week run in, 40 participants using intensified multiple daily injections were randomised to either Dexcom G5 rtCGM or FreeStyle Libre for 8 weeks. The reduction in percentage time spent in hypoglycaemia $<3.3 \mathrm{mmol} / /$ was significantly greater in those using the Dexcom G5 rtCGM compared to FreeStyle Libre $(-4.3 \%$, $p=0.0006)$. However, there was no significant difference in the Gold score or HbA1c from baseline to end point between the groups. They concluded that rtCGM has significantly greater benefit in those with IAH than FreeStyle Libre. These findings lend support to the NICE Type 1 diabetes in adults (NG17) recommendations for the use of rtCGM use in those who have either recurrent severe hypoglycaemia or loss of awareness of hypoglycaemia [6].

The FreeStyle Libre has also been assessed in those with Type 2 diabetes on intensive insulin therapy in a large multi-centre European study of 224 participants [13]. Despite less frequent sensor scans than were seen in IMPACT (8 vs 15 per day), time in hypoglycaemia $(<3.9 \mathrm{mmol} / \mathrm{l})$ reduced by $0.47 \pm 0.13 \mathrm{~h} /$ day compared with controls, representing a $43 \%$ reduction in time spent in hypoglycaemia. HbA1c was unchanged. Treatment satisfaction was higher in users and no device related serious adverse events were reported, suggesting that flash glucose monitoring also offers a suitable replacement to SMBG in those with Type 2 diabetes who are on intensive insulin therapy. 


\section{Observational studies (Table 1)}

Adults:

A range of observational studies have evaluated the FreeStyle Libre. Dover et al prospectively assessed the FreeStyle Libre in 25 participants and described improved glucose control, reduced hypoglycaemia and improved quality of life [14]. The mean $\mathrm{HbA} 1 \mathrm{c}$ of $8.0 \pm 0.14 \%$ (64 $\mathrm{mmol} / \mathrm{mol})$ reduced to $7.5 \% \pm 0.14 \%$ (59 $\mathrm{mmol} / \mathrm{mol})$ after 16 weeks. Those with a baseline $\mathrm{HbA} 1 \mathrm{c}>7.5 \%(58 \mathrm{mmol} / \mathrm{mol})$ experienced a greater $-0.59 \pm 0.15 \%$ reduction. There was a significant reduction in hypoglycaemia and diabetes distress. A key behavioural change associated with FreeStyle Libre use was an increase in those delivering the insulin bolus 15-20 minutes pre-meal as per recommendations. McKnight and Gibb, subsequently reported FreeStyle Libre use in approximately $3 \%$ of their Type 1 diabetes clinic population in Edinburgh [15]. FreeStyle Libre use was associated with a significant change in $\mathrm{HbA} 1 \mathrm{c}$ versus non users $(-0.2 \%$ versus $+0.1 \%$, respectively). Of those with a $\mathrm{HbA} 1 \mathrm{c}>7.5 \%$ ( $>58 \mathrm{mmol} / \mathrm{mol}), 32 \%$ of FreeStyle Libre reached target $\mathrm{HbA} 1 \mathrm{c}$ compared to only $9.8 \%$ of non-users $(p<0.001)$.

A study in Israel of 31 people with poorly controlled Type 1 or Type 2 diabetes noted an $\mathrm{HbA} 1 \mathrm{c}$ decrease of $1.33 \pm 0.29 \%$ after 8 weeks of FreeStyle Libre [16]. For those who continued using the device $(n=27)$, the change was maintained for 24 weeks $(1.21 \pm 0.42 \% ; p=0.009)$.

Holcombe et al (conference abstract) assessed the FreeStyle Libre in a small group of 13 people with Type 1 diabetes [17]. Mean $\mathrm{HbA} 1 \mathrm{c}$ reduced from 75 (9.0\%) to 65 $(8.1 \%) \mathrm{mmol} / \mathrm{mol}$, with increased time in target (29 vs $24 \%$ ) and reduced hypoglycaemia (82 vs 95 minutes). All subjects demonstrated a reduction in their PAID (Problem Areas in Diabetes) scores. Glucose monitoring increased from 3 finger-stick tests per day to 11 scans per day. They also commented in their abstract that the device facilitated virtual contact and support.

\section{Children and young adults:}

Campbell et al. evaluated the use of FreeStyle Libre as a replacement for SMBG in young people ( $4-17$ years) $(n=76,58 \%$ CSII users, $46 \%$ males age $10.3 \pm 4.0$ years, 
baseline HbA1c 7.9 $\pm 1.0 \%$ (63 mmol $/ \mathrm{mol}$ ), T1D duration $5.4 \pm 3.7$ years with Type 1 diabetes in a single arm European multi-centre trial [18]. After 2 weeks' baseline masked (blinded) wear, participants used FreeStyle Libre for 8 weeks. Time in range (70-180 $\mathrm{mg} / \mathrm{dL})$ and $\mathrm{HbA} 1 \mathrm{c}$ significantly improved vs. baseline, 1.0 \pm 2.8 hours/day (mean $\pm S D$ ), $p=0.0056$ and $-0.4 \pm 0.6 \%, p<0.0001$ respectively. Mean FreeStyle Libre scan frequency was 12.9/day, whereas SMBG reduced from a median of 8.0 (baseline) to 1.0/day during open use. Diabetes Treatment Satisfaction Questionnaire showed improved treatment satisfaction for parents $(n=70), 21.7 \pm 6.6$ (mean change score $\pm S D), p<0.0001$ and teens $(13+$ years $)(n=23), 18.7 \pm 5.6$, $p<0.0001$.

These studies add to the growing clinical perception that FreeStyle Libre is desirable and beneficial for people living with Type 1 diabetes. However, it is important to note that improvements seen during observational studies cannot be solely ascribed to the FreeStyle Libre device as other factors such as additional education or simply being observed may contribute to improvements. Nonetheless, the authors have observed striking reductions in $\mathrm{HbA} 1 \mathrm{c}$ with FreeStyle Libre use in those with very poorly controlled diabetes $(\mathrm{HbA} 1 \mathrm{c}>86 \mathrm{mmol} / \mathrm{mol}, 10 \%)$ who are doing little or no glucose monitoring. Unfortunately, such individuals are rarely included in clinical studies.

\section{User satisfaction and insights:}

Adults:

User feedback on FreeStyle Libre is generally very positive. Olafsdottir et al. explored treatment experience in 58 adults with Type 1 diabetes [19]. FreeStyle Libre scored favourably with scores of 9/10 for 'My experience of the FreeStyle Libre was very positive' and 9.4/10 for 'I would like to use FreeStyle Libre in my daily life'. They reported it was easy to use (9.8/10), easy and trouble free insertion (9.1/10) and importantly they felt it was easy to interpret information on the FreeStyle Libre screen (9.6/10). Authors also compared their findings for FreeStyle Libre user satisfaction (overall score 8.22 to 9.8 out of 10) with their earlier studies of Dexcom G4 and Enlite sensor which used the same questions (overall score 72.5 to 90 out of 100 for Dexcom G4 and 42.1 to 86.1 out of 100 for Enlite). 
Ish-Shalom reported their experience in Israel with the FreeStyle Libre [16]. All users ( $n=31$ ) were highly satisfied and stated that they would like to use flash glucose monitoring in the future. In addition, users unanimously stated that it was easy to use and painless. Health care professionals reported that the data presentation, particularly the ambulatory glucose profile (AGP), was an outstanding tool, enabling better and easier control of glucose levels. [16].

\section{Children / Young adults:}

Families of children who have used the device are generally satisfied. McPhater et al contacted the families of 19 FreeStyle Libre users. They reported that the sensor was easy to insert and was an easier method of checking glucose than SMBG (Preliminary analysis, conference abstract) [20]. The majority found the sensor lasted 14 days. Most perceived that glucose control had improved during use due to improved awareness of glucose levels, and changes in self-management behaviour, particularly around hypoglycaemia. Although trend data was useful most users did not alter self-management as a result. Confidence in nocturnal glucose control was improved. One quarter did not continue to use the sensors due to limited sensor duration and blood glucose discrepancies compared to SMBG.

Another user evaluation in the paediatric population also described high user satisfaction with the majority rating the device favourably for sensor application (84.3-92.1\%), sensor wear and use (87.2-100\%), comparing use to SMBG (85.4$97.5 \%)[21]$.

\section{Real-world use of FreeStyle Libre:}

The manufacturer has evaluated the association of the real-world scanning with FreeStyle Libre and glucose control measures. A large number of readers ( $n=50,831$ ) with 279,446 sensors ( 86.4 million monitoring hours by 63.8 million scans) were analysed [22] (Figure 2). Users performed an average of 16.3 scans per day (median:14, interquartile range: $10-20)$. Estimated $\mathrm{HbA1c}$ reduced $(p<0.001)$ as scan rate increased, from $8.0 \%(64 \mathrm{mmol} / \mathrm{mol})$ to $6.7 \%(50 \mathrm{mmol} / \mathrm{mol})$ from the lowest (mean 4.4 scans/day) to highest (mean 48.1 scans/day) groups, while time below $3.9,3.0$ and $2.5 \mathrm{mmol} / \mathrm{l}$ decreased by $15 \%, 40 \%$ and $49 \%$, respectively (all $\mathrm{p}<0.001)$. 


\section{Adverse events:}

As one would expect, most adverse events were related to the medical grade adhesives used to secure the sensor for 14 days. Sensor-wear-related symptoms were recorded as adverse events in the IMPACT trial if the effects were severe and lasted for $>7$ days, or if the user required prescription medication for the event to resolve [11]. IMPACT reported 13 device-related adverse events in 10/119 users in the intervention arm which were related to wearing the sensor, and were categorised as mild (three cases), moderate (four cases), and severe (six cases). Six of 120 intervention arm and one of 121 control arm participants withdrew from the study due to adverse events- For participants with adverse events involving skin symptoms, symptoms (including severe) were resolved by use of barrier products (eg, Cavilon spray) or drug therapy (eg, zinc ointment, Fenistil gel, or hydrocortisone cream), or by relocating the device to another area [23]. Investigations have since identified isobornyl acrylate as the likely agent causing contact dermatitis [24]

Since completion of the IMPACT trial, minor design changes have been made to FreeStyle Libre. These changes are expected to improve breathability of the skin that is in contact with the sensor and to facilitate the exclusion of moisture between the sensor-skin interface [23]. During the children's study, five device related adverse events were reported in five (6\%) participants: allergic reaction, blister, pink mark/scabbing and abrasion on sensor removal [21].

\section{Assessing sensor accuracy}

There are no consensus guidelines for the best metric to assess of accuracy of rtCGM and flash glucose monitoring devices. As a result, a variety have been used, the majority of which are affected by glucose excursions so comparing across studies may lead to misleading conclusions [25]. Ideally different sensors should be compared in the same individual exposed to same glucose fluctuations.

Accuracy of CGM devices is expressed using standards originally designed for assessing the accuracy of SMBG [26]. Numerical accuracy is based on mean or median absolute relative deviation (ARD) (sensor glucose-reference glucose/ reference glucose*100) and/or International Standardization Organisation criteria 
(ISO)[27]. Glucose data are non-normally distributed so median ARD is usually lower than mean ARD. In 2013 International Standardization Organisation criteria (ISO) (ISO: 15197:2013) were drawn up, requiring that $95 \%$ of blood glucose results should be within $\pm 0.83 \mathrm{mmol} / \mathrm{L}$ of laboratory results at concentrations of under 5.6 $\mathrm{mmol} / \mathrm{L}$ or within $\pm 15 \%$ of laboratory results at concentrations of $5.6 \mathrm{mmol} / \mathrm{L}$ or more [27]. In contrast, clinical accuracy is often expressed using the Clarke or consensus error grid analyses [28, 29]. Error grid analyses assign a specific level of clinical risk to any possible error. Each point on the grid (true glucose, measured glucose) is associated with 1 of 5 risk levels. In both, Clarke or consensus error grid error grids, zones $A$ and $B$ errors denote minimal risk to the user.

\section{Accuracy of FreeStyle Libre:}

\section{Accuracy in adults:}

FreeStyle Libre provides interstitial glucose results without the need for finger-stick glucose calibrations. This removes the risk of sensor inaccuracies due to user errors such as not washing hands before a glucose test or delay in glucose entry[30].

In a study funded by the manufacturer, Bailey et. al. assessed the accuracy of FreeStyle Libre in seventy-two study participants with type 1 or type 2 diabetes in four clinical sites in USA [31]. A sensor was inserted on the back of each upper arm for up to 14 days. Three sensor lots were used in the study. There were three scheduled in-clinic visits during the 14-day sensor wear period, where venous blood samples were collected every 15 min over an 8-h period for YSI analyzer (Yellow Springs Instrument, Yellow Springs, $\mathrm{OH}$ ) reference tests. At least eight capillary glucose tests, using the glucose meter built into the reader, were required to be performed on each day of the sensor wear, both at home and in the clinic.

In total, 13,195 capillary glucose and 12,172 YSI reference (venous) results were paired with sensor glucose results. The percentages of results in Zone $A$ of the Consensus and Clarke Error Grids were $86.7 \%$ and $85.5 \%$, respectively. The percentages of sensor results in Zones $A$ and $B$ of the Consensus and Clarke Error Grids were $99.7 \%$ and $99.0 \%$, respectively, whereas $86.2 \%$ and $82.8 \%$ of sensor results were within $0.8 \mathrm{mmol} / \mathrm{l}$ or $20 \%$ of capillary glucose reference and venous 
reference, respectively (percentage within $0.8 \mathrm{mmol} / \mathrm{l}$ or $15 \%$ of reference data not reported).

The overall mean ARD was $11.4 \%$ for sensor results with capillary glucose reference. The overall mean ARD in the clinic alone for sensors' results with capillary glucose reference and with YSI reference was $12.1 \%$ and $12 \%$, respectively. Mean ARD was comparable when the reference glucose was below 100mg/dl and above $100 \mathrm{mg} / \mathrm{dl}$. Looking at the performance of individual sensors approximately $55 \%$ appear to have a mean ARD $<=10 \%$ while about $10 \%$ of sensors had mean ARD values $>=$ to $16 \%$. Percentage of sensor glucose levels in Zone A of the Clarke error grid was lower on day 1 (around 72\%) compared to day 2 to 14 (85\% to $89 \%$ ).

During an independent study, Olafsdottir et. al. assessed the accuracy of the FreeStyle Libre device in fifty-eight adults with type 1 diabetes for 10-14 days and measured capillary blood glucose levels with the HemoCue blood glucose measurement system at least six times a day simultaneously [19]. For the entire study period, the mean ARD was $13.2 \%$. For glucose values $<4,4-10$, and $>10$ $\mathrm{mmol} / \mathrm{L}$, the mean ARD was $20.3 \%, 14.7 \%$, and $9.6 \%$, respectively. Of note, during a post-hoc analysis authors found that $19.9 \%$ of glucose values measured by FreeStyle Libre deviated more than $20 \%$, and $7.9 \%$ of glucose values measured by FreeStyle Libre deviated more than $30 \%$ from the HemoCue reference. Authors have raised concerns about the clinical impact of such high deviations when used for dosing insulin.

\section{Accuracy during OGTT:}

Another study by Fokkert et al. has compared the accuracy of FreeStyle Libre during 14 day home use and during an oral glucose tolerance test [32]. Interestingly they also compared the accuracy of device when worn in the back of the arm and in the abdomen. Percentage of data points in the zone A of the Clarke error grid was significantly higher when the sensors were worn in the back of the arm $(85.5 \%)$ compared to abdomen (64\%). Authors found the FreeStyle Libre tended to report lower results in lower glucose ranges, and higher results than expected in the higher ranges. Following a standardized glucose load, a slower rise in glucose level was 
observed for FreeStyle Libre as compared with reference methods during the first 45-60 min after glucose load ingestion.

\section{Accuracy in children:}

Accuracy of FreeStyle Libre in children has been assessed during a multi-centre UK based study [21]. Those aged 4-17 years, with Type 1 or Type 2 diabetes treated with multiple daily injections of insulin or CSII, and monitoring blood glucose $>2 /$ day were eligible to participate. Participants wore the sensor for up to 14 days and were asked to perform four blood glucose tests daily (FreeStyle Optium test strips, Abbott Diabetes Care), each immediately followed by an interstitial fluid glucose sensor measurement (data masked to participants) to allow comparison of results between sensor and blood glucose. Clarke error grid analysis demonstrated $83.8 \%$ of results in zone $A$ and $99.4 \%$ of results in zones $A$ and $B$. Overall mean ARD was $13.9 \%$, median ARD was $10.4 \%$. For paired results at lower glucose concentrations, with capillary glucose $<5.5 \mathrm{mmol} / \mathrm{L}(\mathrm{n}=1468)$, mean absolute difference (MAD) was 0.75 $\mathrm{mmol} / \mathrm{L}$; for paired results at higher glucose concentrations capillary glucose, 5.5 to $10.0 \mathrm{mmol} / \mathrm{L}$ ( $\mathrm{n}=2090)$, mean ARD was $13.5 \%$; and capillary glucose $>10.0 \mathrm{mmol} / \mathrm{L}$ $(n=1935)$, mean ARD was $10.6 \%$.

\section{Accuracy in pregnant women:}

Scott et. al. have evaluated the accuracy of FreeStyle Libre in 74 women during pregnancy (Type 1 diabetes $n=24$, Type 2 diabetes $n=11$ and gestational diabetes $\mathrm{n}=39$, average gestation was 26 weeks, average age was 30 years, and $66.2 \%$ using insulin) [33]. The study was conducted across 9 UK sites and 4 in Austria. Compared to capillary glucose, consensus Error Grid analysis showed $88.1 \%$ of FreeStyle Libre readings were within zone A and $99.8 \%$ were within zones A \& B. Overall Mean ARD was 11.8\%. Results show good agreement between the FreeStyle Libre and the capillary glucose for pregnant women with diabetes, indicating the device is safe and accurate for use by this population.

\section{Head to head comparison with rtCGM and blood glucose meters}

Aberer et. al. recently compared the FreeStyle Libre with Dexcom G4 Platinum (Dexcom) and Medtronic MiniMed 640G (Medtronic) systems[34]. A total of 12 individuals with Type 1 diabetes were included in a single-centre, open-label study 
over 12 hours. Hypo and hyperglycaemia were induced and venous plasma glucose values measured every 5 minutes for 12 hours. The study also included a short bout of exercise (30 minutes, 50\% VO2 max). Across all glycaemic ranges including exercise, FreeStyle Libre exhibited the lowest and Medtronic the highest mean ARD. The systems fulfilled ISO 15197:2013 criteria by 73.2\% (FreeStyle Libre), 56.1\% (Dexcom) and $52.0 \%$ (Medtronic). The mean ARDs (SD) in the entire glycaemic range were 13.2\% (10.9) (FreeStyle Libre), 16.8\% (12.3) (Dexcom) and 21.4 (17.6) (Medtronic), respectively. All sensors performed less accurately during hypoglycaemia and best during hyperglycaemia.

In another study, Bonora et. al. compared FreeStyle Libre with Dexcom G4 rtCGM sensor upto 14 days in 8 individuals with Type 1 diabetes under usual care conditions [35]. Average glucose profiles and mean ARD versus capillary glucose were broadly similar between the two systems, though the comparative performance varied significantly among individuals. For example, compared with SMBG, participant 5 had a mean ARD of $14.9 \%$ with FreeStyle Libre and mean ARD of $37.4 \%$ with Dexcom G4 sensor. Compared with capillary glucose, range of MARD for FreeStyle Libre among the 8 participants were 10.7 to $20.4 \%$ and with Dexcom G4 ranged from $7 \%$ to $37 \%$ indicating marked heterogeneity. There are no head to head studies comparing FreeStyle Libre device with the latest generation of Dexcom G5 rtCGM.

The accuracy of the Freestyle LIbre, with a MARD of $11.4 \%$ is comparable to many commercially available blood glucose meters. Blood glucose meters should fulfil the ISO criteria but when tested independently this was not found to be the case. Ekhlaspour et al. assessed 17 different commercially available glucose meters against the Yellow Springs reference method (YSI 2300) to determine the MARD. The accuracy varied widely between MARD of $5.6 \%$ to $20.8 \%$. Overall, 9 of 17 meters assessed had a MARD $>12 \%$, raising the possibility that some blood glucose meters could potentially be less accurate than the FreeStyle Libre[36]

\section{Evaluation of FreeStyle Libre with Potentially Interfering Substances:}


The manufacturer has undertaken tests to evaluate the FreeStyle Libre with 16 potentially interfering substances (supplemental table 1) [37]. Testing confirmed no clinically significant interference for the substances tested, with the exception of ascorbic acid and salicylic acid. Taking ascorbic acid may falsely raise and salicylic acid may slightly lower sensor glucose readings. Level of inaccuracy depends on the amount of interfering substance. Detailed information available in supplemental table 1.

\section{Summary of accuracy:}

In conclusion, FreeStyle Libre appears to have comparable accuracy to currently available rtCGM systems such as Dexcom G4 and may even have superior accuracy to Medtronic Enlite sensors, without the need for calibration. A small number of sensors can have higher MARD levels in the range of $16-20 \%$. None of the currently available interstitial glucose sensors meet the ISO 15197:2013 criteria for capillary glucose meters; although in independent testing, many blood glucose meters also fail this criteria.

\section{Adjunctive vs non adjunctive use:}

The term non-adjunctive refers to the use of interstitial glucose data for insulin dosing without the need for additional finger-stick glucose checks. Presently two glucose monitoring systems are licenced for non-adjunctive use in Europe and the USA: Dexcom G5 system and FreeStyle Libre system.

FreeStyle Libre is designed to replace blood glucose testing in the self-management of diabetes including the dosing of insulin except in three main conditions. These are: during rapidly changing glucose values, to confirm sensor-reported hypoglycaemia or impending hypoglycaemia and if symptoms do not correspond with the glucose value displayed. Under these circumstances, the manufacturer advises confirmation with a finger-stick glucose level. Further, Kovatchev and colleagues, using simulation techniques has calculated a minimal accuracy of a mean ARD of $\leq 10 \%$ for rtCGM to reach sufficient safety when sensor glucose data are used for insulin dosing decisions [38]. As outlined in above accuracy studies, a small number of FreeStyle Libre sensors will have a MARD $>15 \%$ and unless the user cross checks with finger-stick glucose it is not possible to know how an 
individual sensor is performing. Accuracy of day 1 of the sensor is lower than other days. A recent statement from the German Diabetes Society, as well as others, have highlighted pros and concerns of using Dexcom G5 / FreeStyle Libre in a nonadjunctive manner[39-41]. FreeStyle Libre users can perform a finger-stick (ideally fasting /when glucose not rapidly changing) to assess sensor accuracy. Also, the Driver and Vehicle Licencing Agency (DVLA) in UK states that blood rather than interstitial glucose should be checked prior to driving [42].

\section{Challenges:}

\section{Funding and reimbursement in UK:}

In November 2017, the FreeStyle Libre became available on prescription in the United Kingdom, bringing it into line with several other European countries (France, Belgium, Sweden among others) where FreeStyle Libre is reimbursed. NICE have published a medtech innovation briefing (MIB) on the FreeStyle Libre [43] and has summarised the utility as well as gaps in the evidence base, including the uncertainties around resource impact which depends upon the extent to which improved glucose control translates into fewer complications, reduced emergency admissions and less use of glucose test strips. However, in England funding is subject to local approval. Given the financial pressures on the NHS, there is concern that variation in local policies for funding will result in inequitable access, further widening variation in diabetes care. In an attempt to overcome this, the Regional Medicine Optimisation Committee (RMOC) have published recommendations for funding in select groups. (https://www.sps.nhs.uk/articles/regional-medicinesoptimisation-committee-freestyle-libre-position-statement/).

\section{Education:}

There is a recognised need for health care professionals to equip themselves with the skills required to support users of both flash glucose monitoring and rtCGM [44]. Health care professionals can be reassured that fundamentally, the skills required to make the most of the data are essentially the same principles as intensive insulin therapy: aiming for a basal insulin which keeps the glucose relatively stable overnight, aiming for insulin: carbohydrate ratios which bring the glucose into target by the next meal and insulin sensitivity factors which correct a higher glucose, bringing it into target 4-5 hours later without causing hypoglycaemia. In the authors 
experience, flash glucose monitoring is an educational tool. Many adjust basal insulin to minimise nocturnal hypoglycaemia and bolus 15-20 minutes pre-meal to reduce post-prandial hyperglycaemia. These behavioural changes reflect the unique insights continuous glucose data provide vs isolated finger-stick glucose levels.

\section{Ambulatory Glucose Profile:}

Flash glucose data can be displayed as an ambulatory glucose profile (AGP) (Figure 3). The AGP displays the data over a 24 hour period with median glucose levels, the 25-75th and 10-90th percentiles as well as excursions and the tendency for hypo or hyperglycaemia throughout the day. This display allows for ease of hypothesis generation, while eliminating "noise" from outliers. An expert group in the USA concluded that standardisation of continuous glucose data reporting using the AGP would be of benefit [45] Matthaei et al have since developed a useful consensus statement on the interpretation of the AGP [46].

\section{Summary and Personal perspectives:}

From the authors' perspective, FreeStyle Libre is a significant advance in the management of diabetes. Many users describe it as 'life changing'. Key advantages and disadvantages are summarised in Table 2. The FreeStyle Libre allows on demand access to glucose data with no need for calibration and no risk of alarm fatigue. The sensor needs replaced infrequently and has a accuracy similar to rtCGM. FreeStyle Libre data can be visualised in multiple devices and platforms as an AGP to aid pattern recognition and insulin dose adjustment. We encourage appropriate education of both users and health care professionals, to harness the full benefits. As a more affordable option for continuous glucose data, we support access to this technology for all people with diabetes who are treated with intensive insulin therapy. Further randomised studies to assess the long-term impact on $\mathrm{HbA} 1 \mathrm{c}$, particularly in those with high baseline $\mathrm{HbA} 1 \mathrm{c}$ and specific age groups such as adolescence and young adults are warranted. 


\section{$\underline{\text { References }}$}

1. Daneman D. Type 1 diabetes. Lancet 2006; 367:847-858.

2. Murata T, Tsuzaki K, Yoshioka F, Okada H, Kishi J, Yamada K, et al. The relationship between the frequency of self-monitoring of blood glucose and glycemic control in patients with type 1 diabetes mellitus on continuous subcutaneous insulin infusion or on multiple daily injections. Journal of diabetes investigation 2015; 6:687-691.

3. Vincze G, Barner JC, Lopez D. Factors associated with adherence to self-monitoring of blood glucose among persons with diabetes. Diabetes Educ 2004; 30:112-125.

4. Mostrom P, Ahlen E, Imberg H, Hansson PO, Lind M. Adherence of self-monitoring of blood glucose in persons with type 1 diabetes in Sweden. BMJ open diabetes research \& care 2017; 5:e000342.

5. Sonksen PH, Judd SL, Lowy C. Home monitoring of blood-glucose. Method for improving diabetic control. Lancet 1978; 1:729-732.

6. National Institute for Health and Care Excellence. Type 1 diabetes in adults: diagnosis and management. https://wwwniceorguk/guidance/ng17 2015.

7. Bode BW, Sabbah H, Davidson PC. What's ahead in glucose monitoring? New techniques hold promise for improved ease and accuracy. Postgrad Med 2001; 109:41-44, 47-49.

8. Beck RW, Riddlesworth T, Ruedy K, Ahmann A, Bergenstal R, Haller S, et al. Effect of Continuous Glucose Monitoring on Glycemic Control in Adults With Type 1 Diabetes Using Insulin Injections: The DIAMOND Randomized Clinical Trial. JAMA 2017; 317:371378.

9. Lind M, Polonsky W, Hirsch IB, Heise T, Bolinder J, Dahlqvist S, et al. Continuous Glucose Monitoring vs Conventional Therapy for Glycemic Control in Adults With Type 1 Diabetes Treated With Multiple Daily Insulin Injections: The GOLD Randomized Clinical Trial. JAMA 2017; 317:379-387.

10. Danne T, Nimri R, Battelino T, Bergenstal RM, Close KL, DeVries JH, et al. International Consensus on Use of Continuous Glucose Monitoring. Diabetes Care 2017; 40:1631-1640.

11. Bolinder J, Antuna R, Geelhoed-Duijvestijn P, Kroger J, Weitgasser R. Novel glucose-sensing technology and hypoglycaemia in type 1 diabetes: a multicentre, nonmasked, randomised controlled trial. Lancet 2016; 388:2254-2263.

12. Reddy M, Jugnee N, El Laboudi A, Spanudakis E, Anantharaja S, Oliver N. A randomized controlled pilot study of continuous glucose monitoring and flash glucose 
monitoring in people with Type 1 diabetes and impaired awareness of hypoglycaemia. Diabet Med 2017.

13. Haak T, Hanaire $H$, Ajjan R, Hermanns N, Riveline JP, Rayman G. Use of Flash Glucose-Sensing Technology for 12 months as a Replacement for Blood Glucose Monitoring in Insulin-treated Type 2 Diabetes. Diabetes therapy : research, treatment and education of diabetes and related disorders 2017; 8:573-586.

14. Dover AR, Stimson RH, Zammitt NN, Gibb FW. Flash Glucose Monitoring Improves Outcomes in a Type 1 Diabetes Clinic. J Diabetes Sci Technol 2017; 11:442-443.

15. McKnight JA, Gibb FW. Flash Glucose Monitoring is associated with improved glycaemic control but use is largely limited to more affluent people in a UK diabetes centre. Diabet Med 2017; 34:732.

16. Ish-Shalom M, Wainstein J, Raz I, Mosenzon O. Improvement in Glucose Control in Difficult-to-Control Patients With Diabetes Using a Novel Flash Glucose Monitoring Device. J Diabetes Sci Technol 2016; 10:1412-1413.

17. Holcombe A, Karunakaran V, Streeting J, Addington H, Smyth S. Trial of FreeStyle Libre in a local service: impact on diabetes outcomes. Diabetic Med 2017; 34:160-160.

18. Campbell F, Kordonouri O, Murphy N, Stewart C. FreeStyle Libre Use for SelfManagement of Diabetes in Children and Adolescents. Diabetes 2017; 66 Suppl. 1A:LB28LB28.

19. Olafsdottir AF, Attvall S, Sandgren U, Dahlqvist S, Pivodic A, Skrtic S, et al. A Clinical Trial of the Accuracy and Treatment Experience of the Flash Glucose Monitor FreeStyle Libre in Adults with Type 1 Diabetes. Diabetes Technol Ther 2017; 19:164-172.

20. McPhater A, Gardiner M, Modgil G. The impact of the Libre device for families and children with Type 1 diabetes. Diabetic Med 2017; 34:104-104.

21. Edge J, Acerini C, Campbell F, Hamilton-Shield J, Moudiotis C, Rahman S, et al. An alternative sensor-based method for glucose monitoring in children and young people with diabetes. Archives of disease in childhood 2017; 102:543-549.

22. Dunn $\mathrm{T}, \mathrm{Xu} \mathrm{Y}$, Hayter $\mathrm{G}$. Evidence of a strong association between frequency of flash glucose monitoring and glucose control measures during real-world usage. Diabetes technology \& therapeutics 2017; 19, Suppl. 1:A12-A12.

23. Bolinder J, Antuna R, Geelhoed-Duijvestijn P, Kroger J, Weitgasser R. Cutaneous adverse events related to FreeStyle Libre device - Authors' reply. Lancet 2017; 389:13961397.

24. Herman A, Aerts O, Baeck M, Bruze M, De Block C, Goossens A, et al. Allergic contact dermatitis caused by isobornyl acrylate in Freestyle $(R)$ Libre, a newly introduced glucose sensor. Contact dermatitis 2017. 
25. Bailey TS. Clinical Implications of Accuracy Measurements of Continuous Glucose Sensors. Diabetes Technol Ther 2017; 19:S51-S54.

26. Clarke W, Kovatchev B. Statistical tools to analyze continuous glucose monitor data. Diabetes Technol Ther 2009; 11 Suppl 1:S45-54.

27. International Organization for Standardization. ISO 15197:2013, In vitro diagnostic test systems -- Requirements for blood-glucose monitoring systems for self-testing in managing diabetes mellitus. https://wwwisoorg/standard/54976htm/ 2013.

28. Clarke WL, Cox D, Gonder-Frederick LA, Carter W, Pohl SL. Evaluating clinical accuracy of systems for self-monitoring of blood glucose. Diabetes Care 1987; 10:622-628.

29. Parkes JL, Slatin SL, Pardo S, Ginsberg BH. A new consensus error grid to evaluate the clinical significance of inaccuracies in the measurement of blood glucose. Diabetes Care 2000; 23:1143-1148.

30. Hoss U, Budiman ES. Factory-Calibrated Continuous Glucose Sensors: The Science Behind the Technology. Diabetes Technology \&amp; Therapeutics 2017; 19:S44-S50.

31. Bailey T, Bode BW, Christiansen MP, Klaff LJ, Alva S. The Performance and Usability of a Factory-Calibrated Flash Glucose Monitoring System. Diabetes Technology \&amp; Therapeutics 2015; 17:787-794.

32. Fokkert MJ, van Dijk PR, Edens MA, Abbes S, de Jong D, Slingerland RJ, et al. Performance of the FreeStyle Libre Flash glucose monitoring system in patients with type 1 and 2 diabetes mellitus. Bmj Open Diabetes Research \&amp; Care 2017; 5.

33. Scott E, Kautzky-Willer A. Accuracy evaluation of Freestyle Libre Flash Glucose Monitoring System when used by pregnant women with diabetes. Diabetes technology \& therapeutics 2017; Volume 19, Supplement 1:A84-A84.

34. Aberer F, Hajnsek M, Rumpler M, Zenz S, Baumann PM, Elsayed H, et al. Evaluation of subcutaneous glucose monitoring systems under routine environmental conditions in patients with type 1 diabetes. Diabetes Obesity \&amp; Metabolism 2017; 19:1051-1055.

35. Bonora B, Maran A, Ciciliot S, Avogaro A, Fadini GP. Head-to-head comparison between flash and continuous glucose monitoring systems in outpatients with type 1 diabetes. Journal of endocrinological investigation 2016; 39:1391-1399.

36. Ekhlaspour L, Mondesir D, Lautsch N, Balliro C, Hillard M, Magyar K, et al. Comparative Accuracy of 17 Point-of-Care Glucose Meters. J Diabetes Sci Technol 2017; 11:558-566.

37. Abbott Diabetes Care. Evaluation of Abbott Diabetes Care FreeStyle Libre Flash Glucose Monitoring System with Potentially Interfering Substances: Document number EDMS025771. Data on file 2017. 
38. Kovatchev BP, Patek SD, Ortiz EA, Breton MD. Assessing sensor accuracy for nonadjunct use of continuous glucose monitoring. Diabetes Technol Ther 2015; 17:177-186.

39. Freckmann G, Schluter S, Heinemann L, Diabetes Technology Working Group of the German Diabetes S. Replacement of Blood Glucose Measurements by Measurements With Systems for Real-Time Continuous Glucose Monitoring (rtCGM) or CGM With Intermittent Scanning (iscCGM): A German View. J Diabetes Sci Technol 2017; 11:653-656.

40. Shapiro AR. Nonadjunctive Use of Continuous Glucose Monitors for Insulin Dosing: Is It Safe? J Diabetes Sci Technol 2017; 11:833-838.

41. Price D. Commentary Regarding Shapiro, "Nonadjunctive Use of Continuous Glucose Monitors for Insulin Dosing: Is It Safe?". J Diabetes Sci Technol 2017; 11:839-841.

42. Driver and Vehicle Licensing Agency (DVLA). Assessing fitness to drive - a guide for medical professionals. https://wwwgovuk/government/uploads/system/uploads/attachment_data/file/596959/assessi ng-fitness-to-drive-a-guide-for-medical-professionalspdf 2017.

43. National Institute for Health and Care Excellence. FreeStyle Libre for glucose monitoring. https://wwwniceorguk/advice/mib110 2017.

44. Diabetes UK. Diabetes UK Consensus Guideline for Flash Glucose Monitoring. https://wwwdiabetesorguk/resources-s3/2017-

09/1190_Flash\%20glucose\%20monitoring\%20guideline_SB_V9\%5B4\%5Dpdf?_ga=213708 337613396328401505301182-20569738801505301182 $201 \overline{7}$.

45. Bergenstal RM, Ahmann AJ, Bailey T, Beck RW, Bissen J, Buckingham B, et al. Recommendations for standardizing glucose reporting and analysis to optimize clinical decision making in diabetes: the Ambulatory Glucose Profile (AGP). Diabetes Technol Ther 2013; 15:198-211.

46. Matthaei S, Antuña DeAlaiz R, Bosi E, Evans M, Geelhoed-Duijvestijn N, Jouber M. Consensus recommendations for the use of Ambulatory Glucose Profile in clinical practice. The British Journal of Diabetes 2014; 14:153-157. 
Table 1: Summary of randomised and observation studies of Freestyle Libre evaluating changes in the $\mathrm{HbA1C}$ and/or hypoglycaemia

\begin{tabular}{|c|c|c|c|}
\hline Reference & Study population & $\begin{array}{l}\text { Intervention and } \\
\text { duration }\end{array}$ & Outcomes \\
\hline \multicolumn{4}{|c|}{ Randomised Controlled Trials } \\
\hline $\begin{array}{l}\text { Bolinder et. al } \\
\text { (11) }\end{array}$ & $\begin{array}{l}\text { Adults with T1D, } \\
\text { HbA1c } \leq 7.5 \% \text { and } \\
\text { intact awareness of } \\
\text { hypoglycaemia. }\end{array}$ & $\begin{array}{l}\text { Parallel groups. FSL } \\
(n=120) \text { vs. self- } \\
\text { monitoring }(n=121) \text { for } \\
6 \text { months. }\end{array}$ & $\begin{array}{l}38 \% \text { reduction in time in hypoglycaemia }(<3.9 \mathrm{mmol} / \mathrm{l}) \text {. No } \\
\text { change in } \mathrm{HbA} 1 \mathrm{c} . \mathrm{FSL} \text { reduced glucose variability; mean } \\
\text { number of scan } 15 / \text { day and mean number of SMBG } 0.5 / \text { day. }\end{array}$ \\
\hline $\begin{array}{l}\text { Reddy et. al. } \\
(12)^{* *}\end{array}$ & $\begin{array}{l}\text { Adults with T1D with } \\
\text { impaired awareness } \\
\text { of hypoglycemia or } \\
\text { severe } \\
\text { hypoglycaemia. }\end{array}$ & $\begin{array}{l}\text { Parallel groups ( } \mathrm{n}=40 \text { ) } \\
\text { FSL vs. real-time CGM } \\
\text { (Dexcom G5) for } 8 \\
\text { weeks. }\end{array}$ & $\begin{array}{l}\text { Higher reduction in } \% \text { time in hypoglycaemia }(<3.3 \mathrm{mmol} / \mathrm{I}) \text { from } \\
\text { baseline to endpoint with } \mathrm{G} 5-\text { median difference between } \\
\text { groups }-4.3 \%, p=0.006 \text {. }\end{array}$ \\
\hline $\begin{array}{l}\text { Haak et. al. } \\
\text { (13) }\end{array}$ & $\begin{array}{l}\text { Adults with T2D with } \\
\text { HbA1c level } 7.5- \\
12.0 \% \text {, on intensive } \\
\text { insulin therapy. }\end{array}$ & $\begin{array}{l}\text { Parallel groups FSL } \\
(n=149) \text { vs. self- } \\
\text { monitoring }(n=75) \text { for } 6 \\
\text { months. }\end{array}$ & $\begin{array}{l}43 \% \text { reduction in time in hypoglycaemia }(<3.9 \mathrm{mM}, \mathrm{p}<0.01) \text {. No } \\
\text { change in } \mathrm{HbA} 1 \mathrm{c} . \mathrm{FSL} \text { reduced glucose variability; mean } \\
\text { number of scan } 8 / \text { day and mean number of SMBG } 0.3 / \text { day. }\end{array}$ \\
\hline \multicolumn{4}{|c|}{ Observational Studies } \\
\hline $\begin{array}{l}\text { Dover et. al. } \\
\text { (14) }\end{array}$ & Adults with T1D & $\begin{array}{l}16 \text { weeks, Use of FSL } \\
\text { under routine care } \\
(n=25)\end{array}$ & $\begin{array}{l}\text { Mean } \mathrm{HbA} 1 \mathrm{c} \text { reduced from of } 8.0 \% \text { to } 7.5 \%(-0.48 \%, p<0.01) \text {. } \\
\text { Episodes of hypoglycaemia }<4.0 \mathrm{mM} \text { reduced from } 17 \text { in the } \\
\text { first } 2 \text { weeks to } 12 \text { in the final } 2 \text { weeks of use }(p=0.19) \text {. } \\
\text { Significant reduction in the Diabetes Distress Scale }(p<0.01) \text {. }\end{array}$ \\
\hline $\begin{array}{l}\text { McKnight et. } \\
\text { al (15) }\end{array}$ & Adults with T1D & $\begin{array}{l}\text { Routine clinic use of } \\
\text { FSL( } n=100 \text { current } \\
\text { users). Duration of } \\
\text { follow-up not available. }\end{array}$ & $\begin{array}{l}\text { HbA1c reduced by }-0.2 \% \text { compared with a } 0.1 \% \text { rise in non- } \\
\text { users. HbA1c }>7.5 \% \text { sub-group, } 32.2 \% \text { of FSL users and } 9.8 \% \\
\text { of non-users }(p<0.01 \text { ) had reached target at their last clinic } \\
\text { visit. }\end{array}$ \\
\hline $\begin{array}{l}\text { Ish-Shalom } \\
\text { et . al (16) }\end{array}$ & $\begin{array}{l}\text { Adults; T2D and T1D } \\
\mathrm{HbA} 1 \mathrm{C} \geq 7.5 \%\end{array}$ & $\begin{array}{l}12 \text { to } 24 \text { weeks use of } \\
\text { FSL }(n=31) \text {. }\end{array}$ & $\begin{array}{l}\mathrm{HbA} 1 \mathrm{c} \text { reduced by }-1.3 \% \text { at } 8 \text { weeks }(p<0.01) \text {. For those } \\
\text { patients who continued using FSL }(n=27) \text {, the change was } \\
\text { maintained for } 24 \text { weeks, }-1.2 \%(p<0.01) \text {. }\end{array}$ \\
\hline Holcombe et & Patients with T1D & FSL use - Duration of & HbA1c improved from $9.0 \%$ to $8.1 \%$. Time spent in target \\
\hline
\end{tabular}




\begin{tabular}{|c|c|c|c|}
\hline al $(17)^{\star \star}$ & & $\begin{array}{l}\text { follow up not specified } \\
(n=13) .\end{array}$ & $\begin{array}{l}\text { increased (24\% vs } 29 \%) \text {, time spent below target reduced } \\
\text { (95min vs } 82 \mathrm{~min}) \text {. }\end{array}$ \\
\hline $\begin{array}{l}\text { Campbell et } \\
\text { al }(18)^{\star *}\end{array}$ & $\begin{array}{l}\text { Children ( } 4 \text { to } 17 \\
\text { years) with T1D }\end{array}$ & $\begin{array}{l}2 \text { weeks masked use } \\
\text { (baseline) followed by } 8 \\
\text { weeks open label use } \\
(n=76) \text {. }\end{array}$ & $\begin{array}{l}\text { Time in range ( } 3.9 \text { to } 10 \mathrm{mM} \text { ) improved vs. baseline by } 1.0 \pm 2.8 \\
\text { hours/day, } \mathrm{p}<0.01 \text {. HbA } 1 \mathrm{c} \text { improved vs. baseline, }-0.4 \pm 0.6 \% \text {, } \\
\mathrm{p}<0.01 \text {. Scan frequency of } \mathrm{FSL} \text { was } 13 / \text { day, SMBG reduced } \\
\text { from } 8.0 \text { to } 1.0 / \text { dav during open use. }\end{array}$ \\
\hline
\end{tabular}

**Conference Abstract.

FSL= Freestyle Libre; T1D= Type 1 Diabetes; T2D=Type 2 Diabetes; SMBG=Self monitored blood glucose 
Table 2: Advantages and disadvantages of flash glucose monitoring.

\begin{tabular}{|c|c|c|}
\hline & Advantages & Disadvantages \\
\hline $\begin{array}{l}\text { Set up and } \\
\text { ease of } \\
\text { use }\end{array}$ & $\begin{array}{l}\text { User friendly, easy to set up and insert and } \\
\text { generally well tolerated [31]. The 'on demand' } \\
\text { glucose data may be preferable for some to } \\
\text { real-time continuous glucose monitoring } \\
\text { (rtCGM) which features alarms to alert to } \\
\text { rising/falling glucose. }\end{array}$ & $\begin{array}{l}\text { Some experience skin reactions } \\
\text { related to the adhesive or sensor } \\
\text { may fall off within the intended } 14 \\
\text { day use. }\end{array}$ \\
\hline $\begin{array}{l}\text { Hypo- } \\
\text { glycaemia }\end{array}$ & $\begin{array}{l}\text { FreeStyle Libre leads to a reduction in } \\
\text { biochemical hypoglycaemia in patients with } \\
\text { both Type } 1 \text { and Type } 2 \text { diabetes }[11,13] \text {. } \\
\text { In the IMPACT trial this occurred within the } \\
\text { first } 2 \text { weeks of use, despite no training on } \\
\text { glucose data interpretation. }\end{array}$ & $\begin{array}{l}\text { There is a } \sim 5 \text { minute lag between } \\
\text { FreeStyle Libre and blood glucose. } \\
\text { Therefore, falling blood glucose may } \\
\text { read higher on the reader than blood } \\
\text { glucose. In this instance blood } \\
\text { glucose should be relied on. } \\
\text { Dexcom G5 rtCGM is likely to be } \\
\text { superior to FreeStyle Libre for } \\
\text { reducing hypoglycaemia in those with } \\
\text { impaired awareness (12). }\end{array}$ \\
\hline $\begin{array}{l}\text { Glucose } \\
\text { control }\end{array}$ & $\begin{array}{l}\text { FreeStyle Libre facilitates frequent glucose } \\
\text { monitoring which has been associated with } \\
\text { lower HbA1c }[2,4] \text {. IMPACT randomised } \\
\text { controlled trial demonstrated increased time } \\
\text { in range and reduced glycaemic variability } \\
\text { while observational studies have reported } \\
\text { reduction in HbA1c [14,15,16, 17, 18]. } \\
\text { Provides insight into glycaemic variability, } \\
\text { easily viewed as an ambulatory glucose } \\
\text { profile in clinic. } \\
\text { Due to low cost can also be used } \\
\text { intermittently, for instance for } 2 \text { weeks pre- } \\
\text { clinic to provide detailed insight into glucose } \\
\text { levels. }\end{array}$ & $\begin{array}{l}\text { FreeStyle Libre use is associated } \\
\text { with lower HbA1c in observational } \\
\text { studies. However, to date no } \\
\text { randomised controlled trials have } \\
\text { demonstrated a reduction in HbA1c. } \\
\text { Bolus calculators are useful tools } \\
\text { which assist with accurate insulin } \\
\text { dose calculation. The bolus } \\
\text { calculator in the Freestyle Libre } \\
\text { reader requires the user to perform a } \\
\text { finger-stick blood glucose } \\
\text { measurement to use the calculator; } \\
\text { interstitial glucose values cannot be } \\
\text { entered. }\end{array}$ \\
\hline $\begin{array}{l}\text { Finger- } \\
\text { stick } \\
\text { blood } \\
\text { glucose } \\
\text { monitoring }\end{array}$ & $\begin{array}{l}\text { FreeStyle Libre reduces the need for the } \\
\text { NICE recommended } 4-10 \text { blood glucose } \\
\text { finger sticks per day; in IMPACT SMBG } \\
\text { reduced from } 5.5 \text { to } 0.5 \text { tests per day. }\end{array}$ & $\begin{array}{l}\text { Blood glucose must be relied on } \\
\text { when: } \\
\text { - Glucose levels are rapidly } \\
\text { changing } \\
\text { - If hypoglycaemia or impending } \\
\text { hypoglycaemia is displayed } \\
\text { - When scanned glucose results do } \\
\text { not correspond with user } \\
\text { symptoms } \\
\text { - To use the FreeStyle Libre reader } \\
\text { bolus calculator } \\
\text { - For driving as per UK Driver and } \\
\text { Vehicle Licencing Agency (DVLA) } \\
\text { regulations }\end{array}$ \\
\hline $\begin{array}{l}\text { Post- } \\
\text { prandial } \\
\text { glucose }\end{array}$ & $\begin{array}{l}\text { FreeStyle Libre use provides information on } \\
\text { post prandial glucose excursions, leading to } \\
\text { a significant increase in user delivery of } \\
\text { insulin bolus } 15-20 \text { minutes pre-meal (14). }\end{array}$ & $\begin{array}{l}\text { Users need to consider the } \sim 4 \text { hour } \\
\text { action profile of rapid acting insulin } \\
\text { analogues when contemplating the } \\
\text { need for a post-meal insulin } \\
\text { correction dose which carries the risk } \\
\text { of insulin stacking and }\end{array}$ \\
\hline
\end{tabular}




\begin{tabular}{|c|c|c|}
\hline & & hypoglycaemia. \\
\hline Driving & $\begin{array}{l}\text { FreeStyle Libre trend arrows allow corrective } \\
\text { action to be taken, facilitating informed } \\
\text { decision making and hypoglycaemia } \\
\text { avoidance as an adjunct to blood glucose } \\
\text { monitoring in relation to driving. }\end{array}$ & $\begin{array}{l}\text { The Driver and Vehicle Licencing } \\
\text { Agency (DVLA) in the UK currently } \\
\text { requires that blood glucose, not } \\
\text { interstitial glucose, must be checked } \\
\text { and relied on prior to driving (38). }\end{array}$ \\
\hline Accuracy & $\begin{array}{l}\text { Accuracy is similar to other available real } \\
\text { CGM systems, (no data comparing dexcom } \\
\text { G5) although there are few head to head } \\
\text { studies published (33, 34). The FreeStyle } \\
\text { Libre mean absolute relative deviation } \\
\text { (MARD) is lower than many commercially } \\
\text { available blood glucose meters (36). }\end{array}$ & $\begin{array}{l}\text { To ensure the accuracy of the } \\
\text { FreeStyle sensor, a blood glucose in } \\
\text { the fasting state can be useful for } \\
\text { cross-reference as a small number of } \\
\text { sensors may have MARD }>15 \% \text {. }\end{array}$ \\
\hline Calibration & $\begin{array}{l}\text { The FreeStyle Libre does not require } \\
\text { calibration which is a benefit; calibration of } \\
\text { real time CGM requires } 2 \text { or more blood } \\
\text { glucose measurement per day. } \\
\text { Calibration alarms can be an unwelcome } \\
\text { intrusion. }\end{array}$ & $\begin{array}{l}\text { In the event of an inaccurate } \\
\text { FreeStyle Libre sensor, it cannot be } \\
\text { calibrated and should be returned to } \\
\text { the manufacturer for a replacement. }\end{array}$ \\
\hline Alarms & $\begin{array}{l}\text { No alarms, therefore no risk of 'alarm } \\
\text { fatigue'. }\end{array}$ & $\begin{array}{l}\text { The lack of alarms is a concern for } \\
\text { those with impaired awareness of } \\
\text { hypoglycaemia who are likely to be } \\
\text { dependent on alarms to alert them to } \\
\text { impending hypoglycaemia (12). }\end{array}$ \\
\hline $\begin{array}{l}14 \text { day } \\
\text { wear }\end{array}$ & $\begin{array}{l}\text { Replacing the sensor every } 14 \text { days, } \\
\text { compared to every } 6 \text { or } 7 \text { days can reduce } \\
\text { the 'diabetes burden' associated with the } \\
\text { number of tasks needed for diabetes } \\
\text { management. Most report sensor insertion as } \\
\text { quick and painless [31]. }\end{array}$ & $\begin{array}{l}\text { Once placed on the skin, FreeStyle } \\
\text { Libre cannot be moved for } 14 \text { days } \\
\text { which may limit clothing options for } \\
\text { some who prefer to have the device } \\
\text { hidden from view. A minority will } \\
\text { experience skin reactions to the } \\
\text { FreeStyle Libre or sensor may fall off } \\
\text { before } 14 \text { days }\end{array}$ \\
\hline $\begin{array}{l}\text { Data } \\
\text { display }\end{array}$ & $\begin{array}{l}\text { The LibreLink app allows integrated use of } \\
\text { FreeStyle Libre with android smart phones. } \\
\text { The mobile phone is used to scan the sensor } \\
\text { which reads glucose data using near field } \\
\text { communication (NFC), removing the need to } \\
\text { carry an additional reader. LibreLink can be } \\
\text { used to review glucose data, the ambulatory } \\
\text { glucose profile (AGP) and estimated HbA1c, } \\
\text { facilitating user review of results without the } \\
\text { need to download data to a computer. } \\
\text { The LibreLinkUp up also allows parents and } \\
\text { carers to 'follow' the user and their glucose } \\
\text { results remotely using the app on their mobile } \\
\text { phone. }\end{array}$ & $\begin{array}{l}\text { Users should carry blood glucose } \\
\text { monitoring equipment with them as } \\
\text { back up. }\end{array}$ \\
\hline Cost & $\begin{array}{l}\text { Flash glucose monitoring in the UK NHS will } \\
\text { cost } £ 35 \text { per sensor, less than half the price } \\
\text { of alternative CGM systems, potentially } \\
\text { making it more accessible to a greater } \\
\text { proportion of people living with diabetes. At } \\
\text { this price it is cost equivalent to } \sim 8 \text { blood } \\
\text { glucose tests per day. }\end{array}$ & $\begin{array}{l}\text { None of the currently available } \\
\text { randomised controlled trials have } \\
\text { demonstrated cost savings in terms } \\
\text { of reduced acute admissions, HbA1c } \\
\text { or long term complications. }\end{array}$ \\
\hline
\end{tabular}


Figure 1. IMPACT study, Bolinder et. al. (11): Time in hypoglycaemic range during baseline and treatment phase in the intervention group using flash glucose monitoring. Grouped bars indicate analysis performed over 2 week periods and then averaged. Dashed line marks the start of the intervention.

Figure 1. IMPACT study, Bolinder et. al. (11): Time in hypoglycaemic range during baseline and treatment phase in the intervention group using flash glucose monitoring. Grouped bars indicate analysis performed over 2 week periods and then averaged. Dashed line marks the start of the intervention.

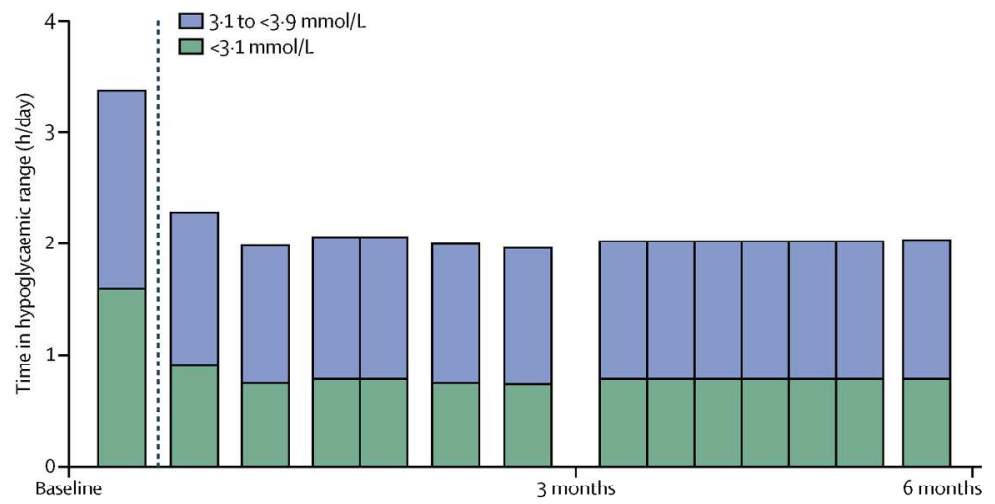

Reprinted from the Lancet, Bolinder J, Antuna R, Geelhoed-Duijvestijn P, Kroger J, Weitgasser R. Novel glucose-sensing technology and hypoglycaemia in type 1 diabetes: a multicentre, non-masked, randomised controlled trial. Lancet 2016; 388:2254 with permission from Elsevier.

$(230 \times 230 \mathrm{DPI})$ 
Figure 2. Dunn et al. Real world data from $>51,000 \mathrm{FSL}$ readers demonstrating an association between glucose monitoring frequency and estimated $\mathrm{HbA} 1 \mathrm{c}$ [22]

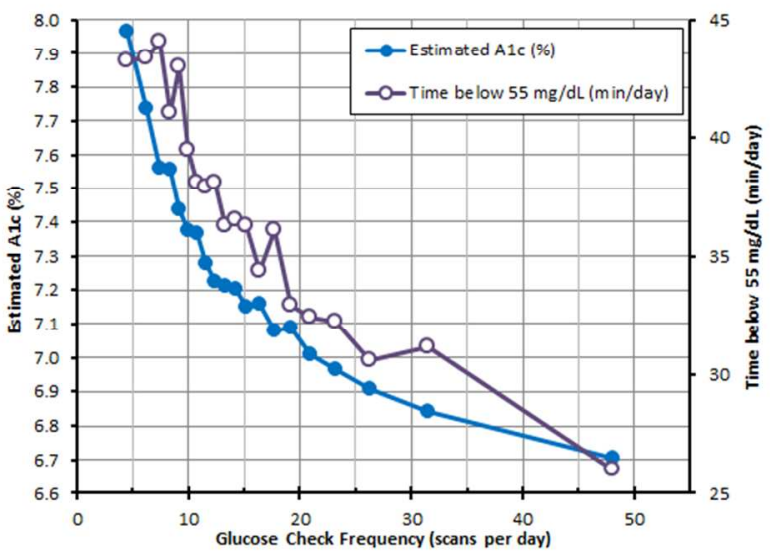

Reproduced with permission from Mary Ann Liebert, Inc. License Number 4195180576968. Abstracts from ATTD 2017 10th International Conference on Advanced Technologies \& Treatments for Diabetes Paris, France-February 15-18, 2017

Figure 2. Dunn et al. Real world data from $>51,000 \mathrm{FSL}$ readers demonstrating an association between glucose monitoring frequency and estimated HbA1c [22].

$254 \times 190 \mathrm{~mm}(300 \times 300 \mathrm{DPI})$ 
Figure 3. Example of an Ambulatory Glucose Profile.

Figure 3. Example of an Ambulatory Glucose Profile.

$338 \times 190 \mathrm{~mm}(230 \times 230 \mathrm{DPI})$ 


\section{Supplemental Table 1: Reproduced with permission from Abbott Diabetes Care \\ Evaluation of Abbott Diabetes Care FreeStyle Libre Flash Glucose Monitoring System with Potentially Interfering Substances:}

Prepared by Abbott Diabetes Care R\&D Technical \& Scientific Support Team, UK

The FreeStyle Libre system has been evaluated with 16 potentially interfering substances. The table below lists the substances evaluated, the therapeutic or normal concentration, and the test concentration of the substance

\begin{tabular}{|c|c|c|c|c|}
\hline \multirow[t]{2}{*}{ Substance } & \multicolumn{2}{|c|}{$\begin{array}{l}\text { Upper Limit of Therapeutic } \\
\text { Concentration or Normal } \\
\text { Concentration }\end{array}$} & \multicolumn{2}{|c|}{$\begin{array}{l}\text { Interferent Test } \\
\text { Concentration }\end{array}$} \\
\hline & $\mathrm{mmol} / \mathrm{L}$ & $\mathrm{mg} / \mathrm{dL}$ & $\mathrm{mmol} / \mathrm{L}$ & $\mathrm{mg} / \mathrm{dL}$ \\
\hline Paracetamol & 0.20 & 3 & 1.32 & 20 \\
\hline Ascorbic Acid & 0.114 & 2.01 & 0.34 & 6.02 \\
\hline $\begin{array}{l}\text { Bilirubin } \\
\text { (unconjugated) }\end{array}$ & 0.02 & 1.23 & 0.34 & 20.01 \\
\hline Cholesterol & 5.18 & 201.24 & 13.0 & 503.1 \\
\hline Creatinine & 0.115 & 1.3 & 2.65 & 30 \\
\hline $\begin{array}{l}\text { Dopamine } \\
\text { Hydrochloride }\end{array}$ & $1.96 \mu \mathrm{mol} / \mathrm{L}$ & 0.03 & 0.85 & 13 \\
\hline Ephedrine & $0.6 \mu \mathrm{mol} / \mathrm{L}$ & 0.01 & 0.61 & 10 \\
\hline Ibuprofen & 0.340 & 7 & 2.42 & 49.96 \\
\hline L-Dopa & 0.010 & 0.2 & 0.25 & 5 \\
\hline Methyldopa & 0.036 & 0.75 & 0.12 & 2.5 \\
\hline Salicylic Acid & 2.17 & 29.95 & 4.34 & 59.89 \\
\hline Tetracycline & 0.011 & 0.5 & 0.09 & 4 \\
\hline Tolazamide & 0.16 & 5 & 3.21 & 100 \\
\hline Tolbutamide & 0.40 & 10.8 & 3.70 & 100 \\
\hline Triglycerides & 5.6 & 500 & 34.0 & 3000 \\
\hline Uric Acid & 0.476 & 8 & 1.40 & 23.52 \\
\hline
\end{tabular}

Interference testing confirmed there was no clinically significant interference for all the substances tested except for ascorbic acid and salicylic acid. Therefore, a limitation has been included in the product labelling for these substances:

Taking ascorbic acid while wearing the sensor may falsely raise your sensor glucose readings. Taking salicylic acid may slightly lower your sensor glucose readings. The level of inaccuracy depends on the amount of the interfering substance active in your body. Ascorbic acid is an endogenous substance, baseline circulating levels of plasma ascorbic acid have been reported as $1.00 \mathrm{mg} / \mathrm{dL}$ $(0.057 \mathrm{mmol} / \mathrm{L})$ for subjects not taking ascorbic acid supplements ${ }^{1}$. Common recommended daily amounts (RDA) of ascorbic acid range from 60 to $120 \mathrm{mg}$. Additional analysis of the effects of supplements resulting in ascorbic acid levels above normal circulating levels was performed ${ }^{2}$.The data suggests that ascorbic acid intake at the maximum of the RDA range may elevate sensor glucose by up to 4.3 $\mathrm{mg} / \mathrm{dL}(0.24 \mathrm{mmol} / \mathrm{L})$ at low glucose concentrations and by up to $1.3 \%$ at high glucose concentrations (when compared to glucose results in the presence of baseline circulating ascorbic acid levels).

The use of salicylic acid for analgesic purposes (1g dose) results in plasma salicylic acid concentrations of $1.7-8.0 \mathrm{mg} / \mathrm{dL}(0.12-0.58$ $\mathrm{mmol} / \mathrm{L})^{3}$ such doses may decrease sensor results by up to $5.5 \%^{2}$

${ }^{1}$ Perrone G, Hideshima T, Ikeda H, Okawa Y, Calabrese E, Gorgun G, Santo L, Cirstea D, Raje N, Chauhan D, Baccarani M, Cavo M, Anderson KC. Ascorbic acid inhibits antitumor activity of bortezomib in vivo. Leukemia 2009;23:1679-1686.

2 Data on file Abbott Diabetes Care.

3 Brantmark B, Wahlin-Boll E, Melander A. Bioavailability of Acetylsalicylic Acid and Salicylic Acid from Rapid- and Slow-Release Formulations, and in Combination with Dipyridamol. European Journal of Clinical Pharmacology 1982;22:309-314. 